Collaborative Information Seeking and Expertise Seeking: Different Discourses about Similar Issues

Hertzum, Morten

Published in:

Journal of Documentation

DOI:

10.1108/JD-04-2016-0053

Publication date:

2017

Document version

Peer reviewed version

Citation for published version (APA):

Hertzum, M. (2017). Collaborative Information Seeking and Expertise Seeking: Different Discourses about Similar Issues. Journal of Documentation, 73(5), 858-976. https://doi.org/10.1108/JD-04-2016-0053 


\title{
Collaborative Information Seeking and Expertise Seeking: Different Discourses about Similar Issues
}

\author{
Morten Hertzum, University of Copenhagen, Denmark, hertzum@hum.ku.dk
}

\section{Abstract}

Purpose - This study compares and contrasts research on collaborative information seeking (CIS) and expertise seeking (EXS) to identify focal themes, blind spots, and possibilities for cross-fertilization.

Design/methodology/approach - Existing research was reviewed. The review consisted of a content analysis of 70 (CIS) and 72 (EXS) studies with respect to the context, scope, process, and setting of $\mathrm{CIS}$ and EXS, supplemented with a bibliometric analysis of the references in the reviewed studies.

Findings - In CIS the context is a group of actors collaborating on a shared task. In EXS the information need is held by an individual but resolved by consulting other people. While the typical scope of EXS studies is source selection, CIS studies mostly concern the consultation of the sources and the use of the obtained information. CIS and EXS studies also attend differentially to the information-seeking process. Only $4 \%$ of the references in the reviewed studies are cited in both CIS and EXS research. We conclude that, at present, CIS and EXS are different discourses about similar issues.

Research limitations/implications - Increased interaction between CIS and EXS will advance research in both areas and prevent duplication of effort. Topics for future research are identified. It should be noted that the findings are limited to the 142 studies reviewed.

Originality/value - By analyzing CIS in the context of EXS, and vice versa, this study provides a fresh look at the information-seeking research that attends to collaboration.

Keywords: collaborative information seeking, collaborative search, expertise seeking, people finding, information behavior

Paper type: Literature review

\section{Introduction}

People frequently exchange information to satisfy information needs and facilitate task progress. Research on such information behaviors needs to cover the fine-grained issues of the emotions associated with information seeking as well as broader issues such as the differences between intra- and inter-organizational information seeking. It needs to account for brief exchanges, for long-term collaborations, and for evolution in the needs and uses of information. It should have something to say about the factors that influence source selection and how these factors interact with the information need. And it should not just offer descriptive accounts but also allow predictions to be made, for 
example about the conditions under which different information systems will be experienced as supportive of the information behaviors.

Two research areas that pursue these challenging issues are collaborative information seeking (CIS; e.g., Fidel et al., 2000, Foster, 2006, Shah, 2014) and expertise seeking (EXS; e.g., Gerstberger and Allen, 1968, Woudstra and Hooff, 2008, Hertzum, 2014). CIS approaches information seeking as an activity performed in a group setting. It has, for example, been defined as "the study of the systems and practices that enable individuals to collaborate during the seeking, searching, and retrieval of information" (Foster, 2006, p. 330). EXS approaches information seeking as an individual activity in which another person is selected as the information source. It has, for example, been defined as "the activity of selecting people as sources for consultation about an information need" (Hertzum, 2014, p. 775). While collaborative information seeking is a fairly recognized label, expertise seeking is also referred to as expert finding or, simply, source selection.

At first sight, CIS and EXS appear to exhibit considerable overlap. They are both about collaboration among people in search of information. The motivation for this study is, however, that beneath the similarities CIS and EXS are quite different. They emerge from different discourses and open for different perspectives on information seeking. In countering the risk that a research area gets "trapped in its own discursive formations" (Wiegand, 1999, p. 24) such differences present a welcome opportunity for reflection. This study aims to compare and contrast $\mathrm{CIS}$ and EXS to expound focal themes, identify blind spots, and explore possibilities for cross-fertilization. Methodologically, the study is a review of existing $\mathrm{CIS}$ and EXS research. Analyzing CIS in the context of EXS, and vice versa, provides a fresh look at the information-seeking research that attends to collaboration (for reviews of either EXS or CIS, see, e.g., Hertzum, 2014, Shah, 2014). The comparative approach also means that the differences between CIS and EXS receive more attention than the commonalities.

In the following we describe the review method employed in this study (Section 2), comparatively analyze the research areas of CIS and EXS (Section 3), and discuss the implications of the analysis for CIS and EXS research (Section 4).

\section{Method}

In this study, CIS and EXS research were compared and contrasted by means of content analysis of existing papers, supplemented with a simple bibliometric analysis. Figure 1 illustrates the process of selecting and coding the papers included in the analyses.

Insert Figure 1 about here

\subsection{Two recent reviews}

The starting point for the selection of the papers to be analyzed was two recent reviews. For CIS, we selected the review by Shah (2014). In the typology of Paré et al. (2015), this paper is a narrative review because an explicit strategy for the selection of the reviewed papers is not presented and because conceptual as well as empirical papers are reviewed. Shah (2014, p. 216) emphasizes that CIS is about "collaboration to help information seeking" as well as about "information seeking to help collaboration". This dual nature of CIS defines the scope of the review. For EXS, we selected the review by Hertzum (2014). In the typology of Paré et al. (2015), this paper is a qualitative systematic review, which implies explicit criteria for the selection of the reviewed papers and a focus on empirical papers. Hertzum (2014) 
identified the research on EXS through a process of (a) inspecting core journals, (b) searching Google Scholar, and (c) inspecting the reference lists of the papers identified in the two previous steps. Both reviews are comprehensive in their coverage, which makes them good candidates for the present analysis. In addition, they are from the same year and can, therefore, be expected to cover recent research equally well.

Hertzum (2014) reviewed 72 EXS papers, which are explicitly referenced in the review. All 72 papers were included in this analysis. The additional 16 references in the review were excluded because they were not about EXS but, for example, about theoretical frameworks that may insert EXS in the broader thinking about human behavior. Of the 99 references in Shah (2014), we excluded 21 papers because they were not about CIS but, for example, about collaboration in general (no focus on information seeking) or individual information seeking (a frequently mentioned contrast to CIS). Books and other monographs were also excluded (5 references). Finally, we had to exclude three workshop papers because they were not retrievable. The remaining 70 papers were included in the analysis.

\subsection{Content analysis}

The content analysis of the 70 (CIS) and 72 (EXS) papers started with reading them. In reading the papers, passages were marked up and annotated, and themes cutting across multiple papers gradually emerged. Some of the themes captured similarities and differences between CIS and EXS studies. Through a process of selection and refinement these themes evolved into categories about why information seeking happened (context), what it encompassed (scope), how it was performed (process), and where it was studied (setting). Table 1 shows the set of categories.

Insert Table 1 about here

The categories about context concerned the way in which collaboration with other people became part of information seeking. Collaboration could either come about in response to an individual person's need for information or it could be the starting point for a group of persons with a shared task or goal. This distinction resulted from comparing annotations about collaboration that already existed at the outset of information seeking with annotations about collaboration that had to be established as part of information seeking. The categories about scope were inspired by the established distinction between information needs, seeking, and use (e.g., King et al., 1994) combined with annotations suggesting that these three elements of information seeking were unevenly distributed in the papers. In addition, multiple annotations of EXS papers noted that seeking was split into the activities of selecting and consulting a source. We adopted this split in our categories about scope. The process categories captured five distinctions important to the performance of CIS and EXS. Two of these distinctions concerned annotations, mostly in CIS papers, that explicitly talked about whether the collaborating persons were co-located or remote and whether their collaboration was synchronous or asynchronous two widely used distinctions in studies of collaborative work (Lee and Paine, 2015). Two other distinctions mainly stemmed from annotations of EXS papers: source accessibility versus source quality and strong versus weak ties. The origin of many of the categories mostly in annotations of either CIS or EXS papers exemplified how contrasting these two strands of research provided fresh looks at CIS and EXS work. The setting categories distinguished between information seeking studied in work, educational, everyday-life, and simulated settings as well as through prototype development and conceptual analysis. We used the setting categories to investigate differences in context, scope, and process across settings. 
To apply the categories systematically the papers were revisited and coded. Context was coded by either one or the other of the two categories. Scope was coded with one or several of the four categories. The categories for process gave pairs of opposing descriptors, such as synchronous/asynchronous. Process was coded by indicating, for each category, whether the paper was primarily about the first descriptor, was primarily about the second descriptor, compared the two descriptors, or could not be categorized with the pair of descriptors. Setting was coded with one of the six categories. In addition to the categories in Table 1 we also used the publication year of the papers to explore the temporal evolution in the number of studies.

\subsection{Bibliometric analysis}

For the bibliometric analysis we included the references from the two reviews and the references of the references. The 70 references from Shah (2014) contained 1903 references for a total of $1973 \mathrm{CIS}$ references. The 72 references from Hertzum (2014) contained 2925 references for a total of 2997 EXS references. In preparation of the analysis duplicate references were identified through a process of automated pattern matching and manual follow-up. The reference set contained 3266 unique references, each cited between 1 and 42 times.

\section{Analysis}

As a precursor to the comparative review of CIS and EXS the analysis starts with a brief overview of each of these two research areas as seen through the categories of the content analysis. This is followed by the comparative review of the context, scope, and process of CIS and EXS. The bibliometric analysis concludes the review.

\subsection{CIS}

CIS research started with three studies in the 1980 s and grew to 16 and 44 studies in the two following decades (Figure 2, top left). This evolution shows increasing interest in the collaborative aspects of information seeking. The low number of studies for the 2010s reflects that the review covers only the first few years of this decade. In terms of settings, CIS studies have mainly addressed work settings (21 studies), prototype development (17), and simulated settings (14), see Figure 2 (top right). A lot of the prototype development concerns prototypes for use during everyday life, so it is noteworthy that only two studies empirically investigate CIS in everyday-life settings.

Figure 2 also shows the distribution of the different categories of context, scope, and process across decades and settings. We analyze the context, scope, and process in detail in Sections 3.3-3.5; here we just look into their evolution over time and their sensitivity to settings. Across decades and settings the context of CIS studies is most often a group of persons with a shared goal or task and only rarely an individual person in need of information (Figure 2, top). For example, the context of information seeking is a group task in all seven studies that have so far been published in the 2010s. Among the categories of scope, it is a similarly stable pattern that studies of source consultation and information use outnumber studies of need recognition and source selection (Figure 2, middle). With respect to the process, Figure 2 (bottom) shows the number of papers categorized with each pair of descriptors. The dimensions of synchronous/asynchronous, co-located/remote, and acquired/received are addressed in most studies, irrespective of decade and setting, while the dimensions of accessibility/quality and strong/weak ties have received less attention. Studies in educational settings constitute an exception to this pattern because they attend rather evenly to the five process dimensions. 
Insert Figure 2 about here

\subsection{EXS}

EXS research started with three studies in the 1960s but did not receive further research attention until the 1980s and has grown to 39 studies in the 2000-09 decade (Figure 3, top left). While the evolution in the number of studies resembles that of CIS, EXS research has predominantly been conducted in work settings (53 studies), see Figure 3 (top right). The absence of prototype development reflects that EXS research defines itself in opposition to research on expertise retrieval, which covers algorithms and prototype development (cf. Hertzum, 2014, Balog et al., 2012). The absence of conceptual analyses reflects a research area inclined to empirical studies.

Across decades and settings a consistent pattern in EXS research has been its starting point in an individual need (Figure 3, top). Only four papers, all published in the 2000-09 decade, have studied EXS in the context of a group task. With respect to scope, source selection dominates in every decade and setting (Figure 3, middle). This pattern is unsurprising because source selection virtually defines EXS research. In most decades and settings the second most frequent scope category is the consultation of the source. That is, EXS is rather narrowly scoped in that the selection and consultation of sources consistently receive more attention than the preceding need recognition and the succeeding information use. For all decades and settings, most of the studies address whether the source is accessible or qualified and whether the information is acquired or received (Figure 3 , bottom). The three other process dimensions are also addressed but by fewer of the studies in each decade and setting. In particular, the dimensions of synchronous/asynchronous and co-located/remote are rarely considered in examining the relationship between seeker and source. Because the categories of context, scope, and process display consistent patterns across decades and settings, for both CIS and EXS, we conduct the remainder of the analysis without distinguishing between decades and between settings.

Insert Figure 3 about here

\subsection{Why: the context of CIS and EXS}

In 58 (83\%) of the 70 CIS studies the context for information seeking is a group of persons with a shared goal or task, whereas in 68 (94\%) of the 72 EXS studies it is an individual person in need of information. For example, Dourish and Bellotti (1992, p. 107) set the context of their CIS study by stating the need "to ensure that individual contributions are relevant to the group's activity as a whole, and to evaluate individual actions with respect to group goals and progress". Similarly, Hansen and Järvelin (2005, p. 1101) note that "people act in a social and organizational context together in groups when trying to solve seeking problems". CIS studies emphasize that information seeking is often performed in the context of projects, by groups of people, to make progress on a shared task, with family and friends, on behalf of someone, for mutual benefit, and in other ways as part of collaborative activity. In contrast, Xu et al. (2006, p. 1666) turn information seeking into a personal trait when they in their EXS study write that "human information seeking, like the food foraging of animals, is regarded as an indispensable skill for surviving". Similarly, Culnan $(1985$, p. 302) sets an individual context for her EXS study: "an individual's information-gathering behavior is a function of the information discovered to be available, the ability to use information based on effort, and the usefulness of information based on experience". 
EXS studies employ a distinction between the seeker, who has an information need, and the others, who are possible information sources.

The difference in context is important for at least four reasons. First, the collaborative dynamics of negotiating a shared focus, dividing information-seeking activities among participants, maintaining awareness of the activities of others, and assessing the meaning and usefulness of acquired information are integral to CIS but outside the scope of EXS. In an EXS study, Savolainen (2010) investigated the source-preference criteria of prospective home buyers. The exclusive individual focus of the study is noteworthy because the homes had to satisfy "the needs of the family" (p. 80). A host of collaborative and social issues among the members of the household could be expected to influence home buyers' relevance criteria and source selections, but spouses and other household members remained undiscussed in the paper. When EXS studies address interpersonal issues it is to investigate the relationship between the information seeker and the information source. For example, DePaulo and Fisher (1980) study the psychological costs of asking for help, such as expecting to be perceived as less competent.

Second, the psychological costs of information seeking are near absent in CIS studies. The collaboration in the studied CIS groups is portrayed as smooth and free of tension, apart from the complications of the task. For example, Bruce et al. (2003, p. 241) quote a less experienced engineer sitting next to an expert engineer for saying: "I was sitting right next to him, which was invaluable help. There would have been a lot of things I would have missed, just little things as you go along, little decisions that you have to make. I could just turn to him and [ask] 'should I do this or that or what do you think about that?' And he'll give an opinion, and its immediate feedback, and it really helps." While the ready access to expert feedback was undoubtedly valuable to the quality of the work, the frequent help seeking might also have incurred psychological costs not examined in the paper. Similarly, Olson et al. (1992) investigate collaboration in small-group design meetings. Their categories for classifying meeting behavior focus exclusively on rational activities such as the issues discussed, the alternatives considered, and the evaluative criteria employed. Possible behavioral effects of psychological costs are not examined. These examples suggest that $\mathrm{CIS}$ research attends more to the positive contributions of collaboration than to possible negative side effects.

Third, re-finding is valued differently in CIS and EXS research. EXS research assumes the existence of knowledgeable sources and investigates how seekers select among these and other sources, that is, how they seek to re-find information already known to some sources. While EXS studies remark that documentary sources will not always exist because much information is never written down (e.g., Hertzum and Pejtersen, 2000), human experts are discussed in terms of their level of accessibility and competence, not in terms of whether or not a human expert exists (e.g., Lu and Yuan, 2011, Rosenberg, 1967, Woudstra et al., 2012). If a knowledgeable source does not exist then EXS becomes an inferior strategy because re-finding is no longer possible. A modest number of EXS studies observe that information is created in the interaction between seeker and source and, thereby, temper the statement that EXS is about re-finding. These studies, for example, find that seekers look for commitment (Hertzum, 2000), creative discourse (Zipperer, 1993), and inspiration (Medaille, 2010), not just for information. CIS research views re-finding differently. For example, Fidel et al. (2004) restrict their focus to information not known by any of the collaborating actors. These authors define CIS as "any event in which actors who participated in the same work process collaborated to resolve an information problem that required them to use resources external to their own knowledge" (p. 944). That is, CIS is about finding task-relevant information that no other group member has yet found. Refinding information already known by another group member would be wasted effort. When a group member needs information already known by another group member it is considered more efficient to 
share the information inside the group than to acquire it anew from an external source. To Pickens and Golovchinsky (2007, p. 21) the negative view on re-finding entails that systems for CIS should "support new discovery and exploration".

Fourth, while CIS tends to imply a group task, the collaborating actors may perform some of the information-seeking activities individually or in subgroups. Hertzum (2008, p. 958) makes explicit room for individual and subgroup activities when he defines CIS as "the information-seeking activities performed by actors to inform their collaborative work combined with the collaborative-grounding activities involved in making this information part of the actors' shared understanding of their work". Several CIS studies empirically investigate the division of labor and the information-seeking roles established by collaborating actors to merge their individual contributions into a collaborative product (e.g., Bruce et al., 2003, Prekop, 2002, Sonnenwald, 1996). By allowing for individual and subgroup elements, CIS becomes broader than EXS. It also becomes possible that many EXS instances occur in a CIS context, as is the case in several of the reviewed EXS studies (e.g., Byström, 2002, Hirsh and Dinkelacker, 2004, Morrison, 1993).

There are exceptions to the finding that the context of CIS studies is a group of persons with a shared goal or task and the context of EXS studies an individual person in need of information. The CIS studies with an individual context investigate loosely-knit communities in which the seekers are not in any active sense members of a group with a shared task. Part of these studies investigates collaborative search in which information about a community of searchers is utilized by the algorithm of an information-retrieval system to make community-specific inferences about the relevance of information items (e.g., Smyth et al., 2005). The EXS studies with a collaborative context investigate how source selection is performed or influenced by a group of collaborators rather than an individual seeker. For example, Hyldegård (2009) investigates how a group of students select their information sources over the course of their collaborative project.

\subsection{What: the scope of CIS and EXS}

Figure 4 shows the scope of CIS and EXS studies in terms of their coverage of need recognition, source selection, source consultation, and information use. Overall, CIS is mainly about source consultation (70\%) and information use (66\%), while EXS is mainly about source selection (97\%) and consultation (43\%).

Insert Figure 4 about here

Nearly all EXS studies investigate source selection. For example, Fidel and Green (2004), Medaille (2010), and Hersberger (2001) investigate the source selection of engineers, theater artists, and homeless parents, respectively. The 2 (3\%) EXS studies not about source selection investigate the amount of time that engineers spend seeking, receiving, and giving information (Robinson, 2010) and the role of trust in the use of web-based, community-driven information sources (Kim and Han, 2009). In contrast, only $21 \%$ of the CIS studies treat source selection. Most CIS studies presuppose the existence of known sources and investigate the information-seeking stages subsequent to source selection: source consultation and information use. Some of these studies focus mainly on the work internal to the group of collaborating actors (e.g., Reddy and Jansen, 2008), others on the technologies used in collaboratively consulting sources (e.g., Shah and González-lbáñez, 2010), and still others on how information is received rather than acquired from preselected sources (e.g., Chalmers, 2002). 
Awareness is a prominent concept in the CIS studies about source consultation and information use (e.g., Aneiros and Estivill-Castro, 2003, Dourish and Bellotti, 1992, Heath et al., 2002, Shah and Marchionini, 2010). Collaborating actors must be aware of their colleagues' activities to determine how their own activities need to be dynamically adjusted to align with those of their colleagues. To maintain this awareness, actors monitor their colleagues' activities so as to ascertain their state, progress, and direction, and they make certain aspects of their own activities visible - display them for their colleagues to monitor. While many collaborating actors are skilled at this monitoring and displaying in co-located settings (e.g., Heath et al., 2002), technological support is necessary to maintain awareness in remote collaboration. Multiple CIS studies present web browsers that incorporate facilities for remaining aware of the search activities of remote actors and for communicating with them about the evolving search. For example, SearchTogether (Morris and Horvitz, 2007) combines the results of the collaborating actors' searches into one list of results, which is visible to all and dynamically updated. In addition, the actors' queries are shared and the system provides textual chat. Similarly, Coagmento (Shah and González-Ibáñez, 2010) provides facilities for sharing and recommending web pages, for organizing and synthesizing the retrieved information, and for notifying and communicating about changes and uses of the information. These studies aim to enable collaboration during source consultation and information use by integrating collaboration support in tools already used for information seeking. Source consultation also receives attention in EXS studies but primarily in terms of ratings of how easy sources are to understand and interact with (e.g., Agarwal et al., 2011, Fidel and Green, 2004).

Only 17 (24\%) CIS studies and 10 (14\%) EXS studies address the recognition of information needs. Thus, the starting point of information seeking is outside the scope of the majority of the studies. In addition, several of the studies that address the recognition of information needs limit their treatment of the topic to a listing of frequent types of information need (e.g., Johnson, 2007). For CIS, in particular, the recognition of information needs warrants investigation because need recognition is rich in collaborative aspects such as welcoming new ideas, stimulating constructive criticism, negotiating goal evolution, and maintaining a shared focus. When information needs are addressed it is often by investigating how the characteristics of the task affect information seeking. For example, both Byström (2002) and Reddy and Jansen (2008) find that complex tasks trigger collaborative forms of information seeking. The information needs associated with different subtasks, or the evolution of an information need over time, may trigger transitions back and forth between individual and collaborative activities. The reviewed studies say little about such dynamics.

\subsection{How: the process of CIS and EXS}

Figure 5 characterizes the process of CIS and EXS by the five pairs of opposing descriptors. It is evident that $\mathrm{CIS}$ and EXS studies attend to different process aspects.

Insert Figure 5 about here

The dimensions of synchronous/asynchronous and co-located/remote are addressed in the majority of the CIS studies but only in few EXS studies. For example, González-lbáñez et al. (2012) experimentally compared CIS in an asynchronous condition, a synchronous co-located condition, and two synchronous remote conditions. The information seeking of co-located actors tended to overlap, whereas remote actors tended to divide the work among them and obtain better coverage as a result of less overlap. Asynchronous CIS allowed for independence between actors but they made less collaborative sense of the retrieved information than actors in synchronous CIS. In $54 \%$ of the CIS studies the collaborating 
actors are simultaneously present. These studies include workplace studies in which the actors are also co-located (e.g., Heath et al., 2002) as well as studies in which the actors are in different locations but connected via CIS tools (e.g., Keller et al., 1997). In 57\% of the CIS studies the actors are in different locations. Thus, a frequent focus in CIS studies is to investigate the consequences of geographic separation (e.g., Gutwin and Greenberg, 2002) or try to annul it by means of technology (e.g., Bly et al., 1993). Most of the EXS studies bypass the synchronous/asynchronous and co-located/remote dimensions. These studies investigate information sources and do not consider whether the sources are accessed face to face, on the phone, by email, or through some other channel (e.g., Hardy, 1982). One of the few EXS studies that distinguish consistently between sources and channels is Chakrabarti et al. (1983), who found that information utility was central to source selection and that distance to source was central to channel selection.

A major theme in EXS studies is whether the quality or accessibility of sources determines their selection. As much as $49 \%$ of the EXS studies compare the influence of quality and accessibility on source selection. For example, Yuan et al. (2010) found that quality and accessibility affected source selection to the same extent, and Marton and Choo (2002) found a larger effect of quality than accessibility. Collectively, the EXS studies speak against the early finding by Gerstberger and Allen (1968) that accessibility dominates quality in the selection of information sources. Lu and Yuan (2011) propose that source selection is governed by a sufficiency principle, according to which seekers simultaneously consider multiple factors and aim to strike a balance between quality and accessibility. Only two CIS studies address the influence of both quality and accessibility on source selection (Freyne et al., 2004, Luo and Olson, 2006). In their study Luo and Olson (2006) found that research collaboratories made it possible for scientists to consult quality sources but also that "some social and technical barriers hinder scientists in developing countries from benefiting from collaboratory participation as much as scientists in developed countries" (p. 1047). The CIS studies that address the quality/accessibility dimension are mainly studies about either quality-related (13 studies) or accessibility-related ( 7 studies) issues. For example, Shah et al. (2010) assign collaborating seekers the roles of gatherer or surveyor and show how the investigated CIS tool provides both roles with quality results: the gatherer gets high-precision results, the surveyor highly diverse results. Accessibility remains implicit in this study.

The distinction between strong and weak ties is addressed in 37\% (CIS) and 32\% (EXS) of the studies. Eleven EXS studies compare the use of strong and weak ties as information sources. For example, Hansen (1999) found that strong ties led to shorter project completion times when the information needed by the seeker was complex, but that weak ties led to shorter project completion times when the needed information was not complex. Hansen (1999) explains this differential effect by arguing that strong ties were more costly to maintain than weak ties and that this extra cost was only offset for complex information needs. When CIS studies address the distinction between strong and weak ties, it is mostly because they are about strong ties (e.g., Blake and Pratt, 2006, Olson et al., 1992, Bruce et al., 2003). In these studies the actors collaborate over an extended period of time and it can, probably, be assumed that accessibility barriers such as the psychological costs of asking for help are limited. A possible bias in CIS research is that strong ties may be overrepresented. However, with only $37 \%$ of the CIS papers describing whether the studied ties are strong or weak, too few of the studies provide the information needed to determine whether such a bias is present.

As much as $86 \%$ of the EXS studies are about deliberately acquiring information and $7 \%$ compare the deliberate acquisition of information with unsolicited reception. The predominant focus on deliberately acquired information leaves the sources of unsolicited information under-researched. Nevo et al. (2012) suggest that these sources differ from those of deliberately acquired information. The EXS studies that compare deliberate acquisition with unsolicited reception vary substantially in the amount of unsolicited 
reception relative to deliberate acquisition. Hertzum (2000) found that a mere $11 \%$ of the informationseeking incidents concerned unsolicited information, while $81 \%$ concerned deliberately acquired information. In contrast, Robinson (2010) found that the studied engineers spent $16 \%$ of their working time receiving information they had not requested and only $1.2 \%$ receiving information they had requested. The CIS studies are more evenly balanced between deliberate acquisition (40\%) and unsolicited reception (29\%). The CIS studies about unsolicited information frequently conceptualize the collaborating actors' attention to such information in terms of awareness (e.g., Gutwin and Greenberg, 2002, Simone and Bandini, 2002, Gaver, 1991). The concept of awareness emphasizes that attending to unsolicited information is an active process, not passive reception. Furthermore, $4 \%$ of the CIS studies compare deliberate acquisition and unsolicited reception. For example, Prekop (2002) empirically identified information-seeking roles that differed with respect to acquisition or reception. The information gatherers volunteered or were formally assigned to acquire information about a specific issue on behalf of the studied group. Another role was the information referrer, who directed unsolicited information from outside the group to individual group members. These roles describe how the group aimed to incorporate both solicited and unsolicited information.

\subsection{Two distinct discourses}

Only 139 (4\%) of the 3266 unique references in the bibliometric analysis are cited in both CIS and EXS studies, see Figure 6. Thus, CIS and EXS research draw on largely separate literatures in spite of the similarity of the researched phenomena. The small overlap in references shows that the two research areas exist in parallel with little exchange of theories, methods, and insights. According to the content analysis, more exchange between the two areas would complement rather than duplicate their findings.

Insert Figure 6 about here

The 139 papers cited in both CIS and EXS research include 112 papers that are cited only once in either one or the other of the two research areas. An additional 14 papers are cited two but not three times in both CIS and EXS research. Only $13(9 \%)$ of the 139 papers are cited three or more times in both the 71 CIS papers and the 73 EXS papers. These 13 papers are listed in Table 2.

Insert Table 2 about here

Six of the 13 papers are empirical studies of information seeking. Allen's (1977) book about how information travels in research-and-development organizations is a core reference in CIS as well as EXS. Allen, for example, found that the probability of a person consulting another person for information decreased rapidly with the physical distance between them. It was only within the first 30 meters that distance had any real effect on the frequency of consultation; persons 30 meters apart communicated as rarely as persons much farther apart. The other empirical studies investigated the relationship between task complexity and public administrators' information seeking (Byström and Järvelin, 1995), the importance of trust in software engineers' collaborative selection of their sources (Hertzum, 2002), the intertwinement of people and documentary sources in engineers' information seeking (Hertzum and Pejtersen, 2000), the user's cognitive and affective experience during information seeking (Kuhlthau, 1991), and the high frequency with which software engineers looked for practical experience and 
commitment rather than information (Hertzum, 2000). Another five of the 13 papers are review or model papers. Wilson (1999) provided an overview of influential models of human information behavior, and Dervin and Nilan (1986) reviewed the research on information needs and uses. In contrast to these general-purpose models and reviews, Leckie et al. (1996) presented a model of the information seeking of professionals, Vakkari (2003) reviewed task-based information searching, and Sonnenwald (1999) presented a framework for human information behavior with specific emphasis on the notion of information horizons. Only two of the 13 papers are about research methods. In these papers, Dervin $(1983,1992)$ described her sense-making methodology. It is noteworthy that 11 of the 13 papers are about information seeking, not cross-cutting issues such as methods.

Only two of the ten most cited papers in CIS research appear in Table 2. Five of the ten most cited CIS papers are not cited at all in EXS research (Twidale et al., 1997, Morris and Horvitz, 2007, Morris, 2008, Greenberg and Roseman, 1996, Romano et al., 1999). For EXS research it is only four of the ten most cited papers that appear in Table 2, while the other six are not cited at all in CIS research (O'Reilly, 1982, Gerstberger and Allen, 1968, Rosenberg, 1967, Culnan, 1983, Borgatti and Cross, 2003, Culnan, 1985). This reinforces the finding that $\mathrm{CIS}$ and EXS research are largely distinct discourses.

\section{Discussion}

This review shows that CIS and EXS research complement each other but that the current level of interaction between the two research areas is low in terms of common references. We hope this review will contribute to increased interaction between $\mathrm{CIS}$ and EXS research.

\subsection{The discourses of CIS and EXS}

A barrier to the definition and understanding of CIS is that it has, to a large extent, been defined through an opposition to individual information seeking. This leads to vague definitions because information seeking that involves collaboration in any form tends to qualify as CIS. Relatedly, EXS has mainly been defined through an opposition to seeking information in documentary sources. Thus, any consultation in which people are selected as the sources of information may qualify as EXS. On the one hand, this makes CIS and EXS discourses about similar issues - about collaboration in information seeking. On the other hand, the preceding analysis shows that CIS and EXS attend quite differently to collaboration and interact very little in terms of references. CIS studies tend to presume that information seeking takes place in the context of a group task and that the collaborators already exist as a group. Conversely, the predominant context of EXS studies is an individual person with a need for information and it is a key element of EXS incidents to establish the collaboration between seeker and source. Moreover, $\mathrm{CIS}$ mainly focuses on source consultation and information use, whereas EXS mainly focuses on the selection and consultation of sources.

Need recognition is within the scope of only a minority of the CIS and EXS studies. Thus, the starting point of CIS and EXS activities in people's work, educational, or everyday-life settings is often left unexplored. In addition, few studies document the effect of CIS and EXS activities on downstream outcomes such as the time spent completing projects (Hansen, 1999) or the customer satisfaction with project products (Allen, 1966). By attending little to need recognition and downstream outcomes, CIS and EXS activities become somewhat dissociated from the concerns and particulars of the setting in which people seek information. This dissociation may contribute to explaining why the identified patterns in context, scope, and process are fairly stable across settings. A stronger association with the settings in which CIS and EXS are studied appears to offer two advantages. First, CIS and EXS are means to an end. Because the setting defines the end, knowledge of the setting is conducive to an understanding of how CIS and EXS activities interact with the end to which they are directed. As an 
example of such interactions, Hertzum and Reddy (2015) investigate how organizational procedures shape CIS activities by pre-specifying, to some extent, how information needs will be addressed, who will do it, what criteria to apply, as well as where and when it will happen. The task may be an apt unit for linking CIS and EXS activities to the particulars of the setting, thereby extending existing work on how, for example, task complexity influences CIS and EXS (e.g., Byström, 2002, Reddy and Jansen, 2008). Second, by associating CIS and EXS activities more strongly with the setting it becomes easier to tie CIS and EXS activities to downstream outcomes and, thereby, investigate the cost-effectiveness of CIS and EXS. Such ties may also facilitate the communication between researchers and practitioners.

Studies that combine CIS and EXS will be in a position to investigate the transitions back and forth between activities arising from individual needs and group tasks. Current CIS and EXS research has only started to address these transitions and the events that trigger them (e.g., Reddy and Jansen, 2008). Combining the discourses of CIS and EXS will also necessitate definitional and conceptual work. A possible frame for combining the two discourses is to set EXS incidents in a CIS context. Most work, educational, and everyday-life settings are collaboratively organized so that people, for example, have workgroup colleagues, classmates, and families. Thus, CIS contexts are ubiquitous but vary greatly in their mix of strong and weak ties. Including this mix in the analysis could assist in getting beyond a dichotomy between individual and collaborative information seeking.

\subsection{Implications}

The review points toward several areas for future research. We find the following six areas of particular interest. First, the collaborative aspects of the recognition of information needs are pertinent to $\mathrm{CIS}$ activities, yet under-researched. In a collaborative context, information needs are realized, expressed, stimulated, criticized, negotiated, and otherwise evolved by a group of actors and the dynamics of these activities set the stage for any other CIS activities. Second, CIS research assumes the existence of a group of collaborating actors. The formation of the group resembles source selection in EXS. In many CIS studies the group evolves with the demands of its task; thus, considerations about, for example, the relative influence of quality and accessibility on source selection may be relevant to understanding how CIS processes evolve. Third, EXS research tends to bypass how information seekers form their perceptions of their sources. How do they, for example, form a perception of the quality of an expert compared to that of a group member who knows the context well? Such issues are important to organizational interventions aimed at influencing source selection. Fourth, CIS studies tacitly assume that information seeking benefits from collaboration. However, psychological costs may discourage actors from asking for information and groupthink (Esser, 1998) may direct them toward overly similar information or overly similar interpretations of it. We need studies of how to organize CIS to benefit from collaboration while avoiding the possible drawbacks. Fifth, EXS studies conventionally contrast the use of people as information sources with the use of documentary sources. An equally relevant comparison may exist between the brief consultation with an expert (the typical EXS scenario) and the ongoing collaboration within a group of actors (a CIS scenario). Introducing a new contrast to the typical EXS scenario will pose new research questions. Sixth, EXS and, to some extent, CIS studies assign agency to the seeker. Consequently, the sources of unsolicited information tend to go unnoticed in spite of their importance. EXS research would benefit from attending more to how seekers expose themselves to unsolicited information and how sources assess and select the seekers to which they supply information.

\section{Conclusion}

CIS and EXS are different discourses about the collaborative aspects of information seeking. In CIS research a group of actors collaborate on a shared task; studies mostly concern how the collaborating 
actors consult their sources and make use of the information obtained from them. Conversely, EXS research addresses information needs that are held by individuals but resolved by consulting other people; studies are predominantly about the process of source selection. This review shows that CIS and EXS research complement, rather than duplicate, each other. However, only $4 \%$ of the references in the reviewed papers are cited in both CIS and EXS research. Therefore, this review hopes to contribute to increased interaction between CIS and EXS research. Increased interaction will strengthen research on information seeking by, for example, addressing the transitions between the individual and collaborative elements of information seeking, investigating the costs - psychological and otherwise - of $\mathrm{CIS}$, and assigning more agency to the sources in EXS research.

\section{References}

Agarwal, N.K., Xu, Y. and Poo, D.C.C. (2011), "A context-based investigation into source use by information seekers", Journal of the American Society for Information Science and Technology, Vol. 62 No. 6, pp. 1087-1104.

Allen, T.J. (1966). "The differential performance of information channels in the transfer of technology", in MIT Conference on Human Factors in the Transfer of Technology, MIT, Cambridge, MA.

Allen, T.J. (1977), Managing the flow of technology: Technology transfer and the dissemination of technological information within the R\&D organization, MIT Press, Cambridge, MA.

Aneiros, M. and Estivill-Castro, V. (2003). "Foundations of unconstrained collaborative web browsing with awareness", in Proceedings of the WI2003 International Conference on Web Intelligence, IEEE Press, New York, pp. 18-25.

Balog, K., Fang, Y., Rijke, M.d., Serdyukov, P. and Si, L. (2012), "Expertise retrieval", Foundations and Trends in Information Retrieval, Vol. 6 No. 2\&3, pp. 127-256.

Blake, C. and Pratt, W. (2006), "Collaborative information synthesis I: A model of information behaviors of scientists in medicine and public health", Journal of the American Society for Information Science and Technology, Vol. 57 No. 13, pp. 1740-1749.

Bly, S.A., Harrison, S.R. and Irwin, S. (1993), "Media spaces: Bringing people together in a video, audio, and computing environment", Communications of the ACM, Vol. 36 No. 1, pp. 28-46.

Borgatti, S.P. and Cross, R. (2003), "A relational view of information seeking and learning in social networks", Management Science, Vol. 49 No. 4, pp. 432-445.

Bruce, H., Fidel, R., Pejtersen, A.M., Dumais, S., Grudin, J. and Poltrock, S. (2003), "A comparison of the collaborative information retrieval behaviors of two design teams", New Review of Information Behaviour Research, Vol. 4, pp. 139-153.

Byström, K. (2002), "Information and information sources in tasks of varying complexity", Journal of the American Society for Information Science and Technology, Vol. 53 No. 7, pp. 581-591.

Byström, K. and Järvelin, K. (1995), "Task complexity affects information seeking and use", Information Processing \& Management, Vol. 31 No. 2, pp. 191-213.

Chakrabarti, A.K., Feineman, S. and Fuentevilla, W. (1983), "Characteristics of sources, channels, and contents for scientific and technical information systems in industrial R and D", IEEE Transactions on Engineering Management, Vol. 30 No. 2, pp. 83-88.

Chalmers, M. (2002), "Awareness, representation and interpretation", Computer Supported Cooperative Work, Vol. 11 No. 3, pp. 389-409.

Culnan, M.J. (1983), "Environmental scanning: The effects of task complexity and source accessibility on information gathering behavior", Decision Sciences, Vol. 14 No. 2, pp. 194-206.

Culnan, M.J. (1985), "The dimensions of perceived accessibility to information: Implications for the delivery of information systems and services", Journal of the American Society for Information Science, Vol. 36 No. 5, pp. 302-308. 
DePaulo, B.M. and Fisher, J.D. (1980), "The costs of asking for help", Basic and Applied Social Psychology, Vol. 1 No. 1, pp. 23-35.

Dervin, B. (1983), "An overview of sense-making research: Concepts, methods and results to date", paper presented at the Annual Meeting of the International Communication Association, Dallas, TX.

Dervin, B. (1992). "From the mind's eye of the user: The sense-making qualitative-quantitative methodology", in Glazier, J.D. and Powell, R.R. (eds.), Qualitative Research on Information Management, Libraries Unlimited, Englewood, CO, pp. 61-84.

Dervin, B. and Nilan, M. (1986), "Information needs and uses", Annual Review of Information Science and Technology, Vol. 21, pp. 3-33.

Dourish, P. and Bellotti, V. (1992). "Awareness and coordination in shared workspaces", in Proceedings of the CSCW 1992 Conference on Computer Supported Cooperative Work, ACM Press, New York, pp. 107-114.

Esser, J.K. (1998), "Alive and well after 25 years: A review of groupthink research", Organizational Behavior and Human Decision Processes, Vol. 73 No. 2\&3, pp. 116-141.

Fidel, R., Bruce, H., Pejtersen, A.M., Dumais, S., Grudin, J. and Poltrock, S. (2000), "Collaborative information retrieval (CIR)", New Review of Information Behaviour Research, Vol. 1, pp. 235-247.

Fidel, R. and Green, M. (2004), "The many faces of accessibility: Engineers' perception of information sources", Information Processing \& Management, Vol. 40 No. 3, pp. 563-581.

Fidel, R., Pejtersen, A.M., Cleal, B. and Bruce, H. (2004), "A multidimensional approach to the study of human-information interaction: A case study of collaborative information retrieval", Journal of the American Society for Information Science and Technology, Vol. 55 No. 11, pp. 939-953.

Foster, J. (2006). "Collaborative information seeking and retrieval", in Cronin, B. (ed.) Annual Review of Information Science and Technology, Information Today, Medford, NJ, pp. 329-356.

Freyne, J., Smyth, B., Coyle, M., Balfe, E. and Briggs, P. (2004), "Further experiments on collaborative ranking in community-based web search", Artificial Intelligence Review, Vol. 21 No. 3, pp. 229-252.

Gaver, W.W. (1991). "Sound support for collaboration", in ECSCW 1991: Proceedings of the Second European Conference on Computer-Supported Cooperative Work, Springer, Dordrecht, NL, pp. 293308.

Gerstberger, P.G. and Allen, T.J. (1968), "Criteria used by research and development engineers in the selection of an information source", Journal of Applied Psychology, Vol. 52 No. 4, pp. 272-279.

González-lbáñez, R., Haseki, M. and Shah, C. (2012), "Time and space in collaborative information seeking: The clash of effectiveness and uniqueness", Proceedings of the American Society for Information Science and Technology, Vol. 49 No. 1, pp. 1-10.

Greenberg, S. and Roseman, M. (1996). "GroupWeb: A WWW browser as real time groupware", in Proceedings of the CHI1996 Conference on Human Factors in Computing Systems, ACM Press, New York, pp. 271-272.

Gutwin, C. and Greenberg, S. (2002), "A descriptive framework of workspace awareness for real-time groupware", Computer Supported Cooperative Work, Vol. 11 No. 3, pp. 411-446.

Hansen, M.T. (1999), "The search-transfer problem: The role of weak ties in sharing knowledge across organization subunits", Administrative Science Quarterly, Vol. 44 No. 1, pp. 82-111.

Hansen, P. and Järvelin, K. (2005), "Collaborative information retrieval in an information-intensive domain", Information Processing \& Management, Vol. 41 No. 5, pp. 1101-1119.

Hardy, A.P. (1982), "The selection of channels when seeking information: Cost/benefit vs least-effort", Information Processing \& Management, Vol. 18 No. 6, pp. 289-293.

Heath, C., Svensson, M.S., Hindmarsh, J., Luff, P. and vom Lehn, D. (2002), "Configuring awareness", Computer Supported Cooperative Work, Vol. 11 No. 3\&4, pp. 317-347. 
Hersberger, J. (2001), "Everyday information needs and information sources of homeless parents", New Review of Information Behaviour Research, Vol. 2, pp. 119-134.

Hertzum, M. (2000), "People as carriers of experience and sources of commitment: Information seeking in a software design project", New Review of Information Behaviour Research, Vol. 1, pp. 135-149.

Hertzum, M. (2002), "The importance of trust in software engineers' assessment and choice of information sources", Information \& Organization, Vol. 12 No. 1, pp. 1-18.

Hertzum, M. (2008), "Collaborative information seeking: The combined activity of information seeking and collaborative grounding", Information Processing \& Management, Vol. 44 No. 2, pp. 957-962.

Hertzum, M. (2014), "Expertise seeking: A review", Information Processing \& Management, Vol. 50 No. 5, pp. 775-795.

Hertzum, M. and Pejtersen, A.M. (2000), "The information-seeking practices of engineers: Searching for documents as well as for people", Information Processing \& Management, Vol. 36 No. 5, pp. 761778.

Hertzum, M. and Reddy, M. (2015). "Procedures and collaborative information seeking: A study of emergency departments", in Hansen, P., Shah, C. and Klas, C.-P. (eds.), Collaborative Information Seeking: Best Practices, New Domains and New Thoughts, Springer, Berlin, pp. 55-71.

Hirsh, S. and Dinkelacker, J. (2004), "Seeking information in order to produce information: An empirical study at Hewlett Packard Labs", Journal of the American Society for Information Science and Technology, Vol. 55 No. 9, pp. 807-817.

Hyldegård, J. (2009), "Beyond the search process - Exploring group members' information behavior in context", Information Processing \& Management, Vol. 45 No. 1, pp. 142-158.

Johnson, C.A. (2007), "Social capital and the search for information: Examining the role of social capital in information seeking behavior in Mongolia", Journal of the American Society for Information Science and Technology, Vol. 58 No. 6, pp. 883-894.

Keller, R.M., Wolfe, S.R., Chen, J.R., Rabinowitz, J.L. and Mathe, N. (1997), "A bookmarking service for organizing and sharing URLs", Computer Networks and ISDN Systems, Vol. 29 No. 8-13, pp. 11031114.

Kim, B. and Han, I. (2009), "The role of trust belief and its antecedents in a community-driven knowledge environment", Journal of the American Society for Information Science and Technology, Vol. 60 No. 5, pp. 1012-1026.

King, D.W., Casto, J. and Jones, H. 1994. Communication by engineers: A literature review of engineers' information needs, seeking processes, and use. Washington, DC: Council on Library Resources.

Kuhlthau, C.C. (1991), "Inside the search process: Information seeking from the user's perspective", Journal of the American Society for Information Science, Vol. 42 No. 5, pp. 361-371.

Leckie, G.J., Pettigrew, K.E. and Sylvain, C. (1996), "Modeling the information seeking of professionals: A general model derived from research on engineers, health care professionals, and lawyers", Library Quarterly, Vol. 66 No. 2, pp. 161-193.

Lee, C.P. and Paine, D. (2015). "From the matrix to a model of coordinated action (MoCA): A conceptual framework of and for CSCW", in Proceedings of the CSCW 2015 Conference on Computer Supported Cooperative Work, ACM Press, New York, pp. 179-194.

Lu, L. and Yuan, Y.C. (2011), "Shall I google it or ask the competent villain down the hall? The moderating role of information need in information source selection", Journal of the American Society for Information Science and Technology, Vol. 62 No. 1, pp. 133-145.

Luo, A. and Olson, J.S. (2006). "Informal communication in collaboratories", in CHI 2006 Extended Abstracts on Human Factors in Computing Systems, ACM Press, New York, pp. 1043-1048.

Marton, C. and Choo, C.W. (2002). "A question of quality: The effect of source quality on information seeking by women in IT professions", in ASIST2002: Proceedings of the 65th Annual Meeting of the 
American Society for Information Science and Technology, Information Today, Medford, NJ, pp. 140-151.

Medaille, A. (2010), "Creativity and craft: The information-seeking behavior of theatre artists", Journal of Documentation, Vol. 66 No. 3, pp. 327-347.

Morris, M.R. (2008). "A survey of collaborative web search practices", in Proceedings of the CHI2008 Conference on Human Factors in Computing Systems, ACM Press, New York, pp. 1657-1660.

Morris, M.R. and Horvitz, E. (2007). "SearchTogether: An interface for collaborative web search", in Proceedings of the UIST'07 Symposium on User Interface Software and Technology, ACM Press, New York, pp. 3-12.

Morrison, E.W. (1993), "Newcomer information seeking: Exploring types, modes, sources, and outcomes", Academy of Management Journal, Vol. 36 No. 3, pp. 557-589.

Nevo, D., Benbasat, I. and Wand, Y. (2012), "The knowledge demands of expertise seekers in two different contexts: Knowledge allocation versus knowledge retrieval", Decision Support Systems, Vol. 53 No. 3, pp. 482-489.

O'Reilly, C.A. (1982), "Variations in decision makers' use of information sources: The impact of quality and accessibility of information", Academy of Management Journal, Vol. 25 No. 4, pp. 756-771.

Olson, G.M., Olson, J.S., Carter, M.R. and Storrøsten, M. (1992), "Small group design meetings: An analysis of collaboration", Human-Computer Interaction, Vol. 7 No. 4, pp. 347-374.

Paré, G., Trudel, M.-C., Jaana, M. and Kitsiou, S. (2015), "Synthesizing information systems knowledge: A typology of literature reviews", Information \& Management, Vol. 52 No. 2, pp. 183-199.

Pickens, J. and Golovchinsky, G. (2007). "Collaborative exploratory search", in Proceedings of the HCIR2007 Workshop on Human-Computer Interaction and Information Retrieval, MIT, Cambridge, MA, pp. 21-22.

Prekop, P. (2002), "A qualitative study of collaborative information seeking", Journal of Documentation, Vol. 58 No. 5, pp. 533-547.

Reddy, M. and Jansen, B.J. (2008), "A model for understanding collaborative information behavior in context: A study of two healthcare teams", Information Processing \& Management, Vol. 44 No. 1, pp. 256-273.

Robinson, M.A. (2010), "An empirical analysis of engineers' information behaviors", Journal of the American Society for Information Science and Technology, Vol. 61 No. 4, pp. 640-658.

Romano, N.C., Roussinov, D., Nunamaker, J.F. and Chen, H. (1999). "Collaborative information retrieval environment: Integration of information retrieval with group support systems", in HICSS 1999: Proceedings of the 32nd Hawaii International Conference on System Sciences, IEEE Press, Washington, DC.

Rosenberg, V. (1967), "Factors affecting the preferences of industrial personnel for information gathering methods", Information Storage and Retrieval, Vol. 3 No. 3, pp. 119-127.

Savolainen, R. (2010), "Source preference criteria in the context of everyday projects: Relevance judgments made by prospective home buyers", Journal of Documentation, Vol. 66 No. 1, pp. 70-92.

Shah, C. (2014), "Collaborative information seeking", Journal of the Association for Information Science and Technology, Vol. 65 No. 2, pp. 215-236.

Shah, C. and González-Ibáñez, R. (2010), "Exploring information seeking processes in collaborative search tasks", ASIS\&T2010: Proceedings of the American Society for Information Science and Technology, Vol. 47, pp. 1-7.

Shah, C. and Marchionini, G. (2010), "Awareness in collaborative information seeking", Journal of the American Society for Information Science and Technology, Vol. 61 No. 10, pp. 1970-1986.

Shah, C., Pickens, J. and Golovchinsky, G. (2010), "Role-based results redistribution for collaborative information retrieval", Information Processing \& Management, Vol. 46 No. 6, pp. 773-781. 
Simone, C. and Bandini, S. (2002), "Integrating awareness in cooperative applications through the reaction-diffusion metaphor", Computer Supported Cooperative Work, Vol. 11 No. 3, pp. 495-530.

Smyth, B., Balfe, E., Boydell, O., Bradley, K., Briggs, P., Coyle, M. and Freyne, J. (2005). "A live-user evaluation of collaborative web search", in IJCAI2005: Proceedings of the 19th International Joint Conference on Artificial Intelligence, Morgan Kaufmann, San Francisco, CA, pp. 1419-1424.

Sonnenwald, D.H. (1996), "Communication roles that support collaboration during the design process", Design Studies, Vol. 17 No. 3, pp. 277-301.

Sonnenwald, D.H. (1999). "Evolving perspectives of human information behavior: Contexts, situations, social networks and information horizons", in Wilson, T.D. and Allen, D. (eds.), Proceedings of the Second International Conference on Research in Information Needs, Seeking and Use in Different Contexts, Taylor Graham, London, pp. 176-190.

Twidale, M.B., Nichols, D.M. and Paice, C.D. (1997), "Browsing is a collaborative process", Information Processing \& Management, Vol. 33 No. 6, pp. 761-783.

Vakkari, P. (2003), "Task-based information searching", Annual Review of Information Science and Technology, Vol. 37, pp. 413-464.

Wiegand, W.A. (1999), "Tunnel vision and blind spots: What the past tells us about the present; reflections on the twentieth-century history of American librarianship", Library Quarterly, Vol. 69 No. 1, pp. 1-32.

Wilson, T.D. (1999), "Models in information behaviour research", Journal of Documentation, Vol. 55 No. 3, pp. 249-270.

Woudstra, L. and Hooff, B.v.d. (2008), "Inside the source selection process: Selection criteria for human information sources", Information Processing \& Management, Vol. 44 No. 3, pp. 1267-1278.

Woudstra, L., Hooff, B.v.d. and Schouten, A.P. (2012), "Dimensions of quality and accessibility: Selection of human information sources from a social capital perspective", Information Processing \& Management, Vol. 48 No. 4, pp. 618-630.

$\mathrm{Xu}$, Y., Tan, C.Y. and Yang, L. (2006), "Who will you ask? An empirical study of interpersonal task information seeking", Journal of the American Society for Information Science and Technology, Vol. 57 No. 12, pp. 1666-1677.

Yuan, Y.C., Carboni, I. and Ehrlich, K. (2010), "The impact of awareness and accessibility on expertise retrieval: A multilevel network perspective", Journal of the American Society for Information Science and Technology, Vol. 61 No. 4, pp. 700-714.

Zipperer, L. (1993), "The creative professional and knowledge", Special Libraries, Vol. 84 No. 2, pp. 6978. 
Table 1. Category definitions for the content analysis

\begin{tabular}{|c|c|}
\hline Category & Definition \\
\hline \multicolumn{2}{|l|}{ Context (why) } \\
\hline Individual need & Individual person in need of information \\
\hline Group task & Group of persons with a shared goal or task \\
\hline \multicolumn{2}{|l|}{ Scope (what) } \\
\hline Recognizing info need & Becoming aware of a knowledge gap that prevents progress in a task \\
\hline Selecting source & $\begin{array}{l}\text { Identifying, selecting, and establishing contact with an information } \\
\text { source }\end{array}$ \\
\hline Consulting source & $\begin{array}{l}\text { Interacting with the source to seek and acquire information, } \\
\text { including advice, ideas, and other input }\end{array}$ \\
\hline Using information & Using the acquired information to move the task forward \\
\hline \multicolumn{2}{|l|}{ Process (how) } \\
\hline Synchronous / asynchronous & $\begin{array}{l}\text { Are the seeker and the source present at the same time or at } \\
\text { different points in time? }\end{array}$ \\
\hline Co-located / remote & $\begin{array}{l}\text { Are the seeker and the source at the same physical location or at } \\
\text { different locations? }\end{array}$ \\
\hline Accessibility / quality & Is accessibility or quality more important to the choice of source? \\
\hline Strong / weak tie & Are the seeker and the source strongly or weakly related? \\
\hline Acquired / received & $\begin{array}{l}\text { Is the information deliberately acquired or is it received without } \\
\text { being solicited? }\end{array}$ \\
\hline \multicolumn{2}{|l|}{ Setting (where) } \\
\hline Work & An organizational setting in which the participants earn their living \\
\hline Education & $\begin{array}{l}\text { A study setting in which the participants follow classes, write theses, } \\
\text { and so forth }\end{array}$ \\
\hline Everyday life & $\begin{array}{l}\text { A personal setting comprising the participants' work, education, } \\
\text { leisure, and other activities }\end{array}$ \\
\hline Simulation & An artificial setting, such as a scenario or a laboratory experiment \\
\hline Prototype development & $\begin{array}{l}\text { A study in which the empirical content consists of developing a } \\
\text { prototype }\end{array}$ \\
\hline Conceptual & A conceptual analysis with no empirical content \\
\hline
\end{tabular}


Table 2. Papers cited at least three times in both CIS and EXS research

\begin{tabular}{|c|c|c|c|}
\hline \multirow[t]{2}{*}{ Reference } & \multirow[t]{2}{*}{ Title } & \multicolumn{2}{|c|}{ Citations } \\
\hline & & $\mathrm{CIS}$ & EXS \\
\hline Allen (1977) & $\begin{array}{l}\text { Managing the flow of technology: Technology transfer and the } \\
\text { dissemination of technological information within the R\&D } \\
\text { organization }\end{array}$ & $13^{*}$ & $29 *$ \\
\hline $\begin{array}{l}\text { Byström and Järvelin } \\
\text { (1995) }\end{array}$ & Task complexity affects information seeking and use & 4 & $10^{*}$ \\
\hline Dervin (1992) & $\begin{array}{l}\text { From the mind's eye of the user: The sense-making qualitative- } \\
\text { quantitative methodology }\end{array}$ & 4 & 6 \\
\hline Hertzum (2002) & $\begin{array}{l}\text { The importance of trust in software engineers' assessment and } \\
\text { choice of information sources }\end{array}$ & 4 & 6 \\
\hline Wilson (1999) & Models in information behaviour research & 5 & 4 \\
\hline Leckie et al. (1996) & $\begin{array}{l}\text { Modeling the information seeking of professionals: A general } \\
\text { model derived from research on engineers, health care } \\
\text { professionals, and lawyers }\end{array}$ & 3 & $13^{*}$ \\
\hline $\begin{array}{l}\text { Hertzum and Pejtersen } \\
(2000)\end{array}$ & $\begin{array}{l}\text { The information-seeking practices of engineers: Searching for } \\
\text { documents as well as for people }\end{array}$ & 3 & $12 *$ \\
\hline Kuhlthau (1991) & $\begin{array}{l}\text { Inside the search process: Information seeking from the user's } \\
\text { perspective }\end{array}$ & $9 *$ & 3 \\
\hline Dervin (1983) & $\begin{array}{l}\text { An overview of sense-making research: Concepts, methods } \\
\text { and results to date }\end{array}$ & 3 & 6 \\
\hline Dervin and Nilan (1986) & Information needs and uses & 3 & 4 \\
\hline Vakkari (2003) & Task-based information searching & 4 & 3 \\
\hline Hertzum (2000) & $\begin{array}{l}\text { People as carriers of experience and sources of commitment: } \\
\text { Information seeking in a software design project }\end{array}$ & 3 & 3 \\
\hline Sonnenwald (1999) & $\begin{array}{l}\text { Evolving perspectives of human information behavior: } \\
\text { Contexts, situations, social networks and information horizons }\end{array}$ & 3 & 3 \\
\hline
\end{tabular}

$\mathrm{CIS}$ - Collaborative information seeking, EXS - Expertise seeking, * The paper is among the ten most cited in CIS, or EXS, research. 


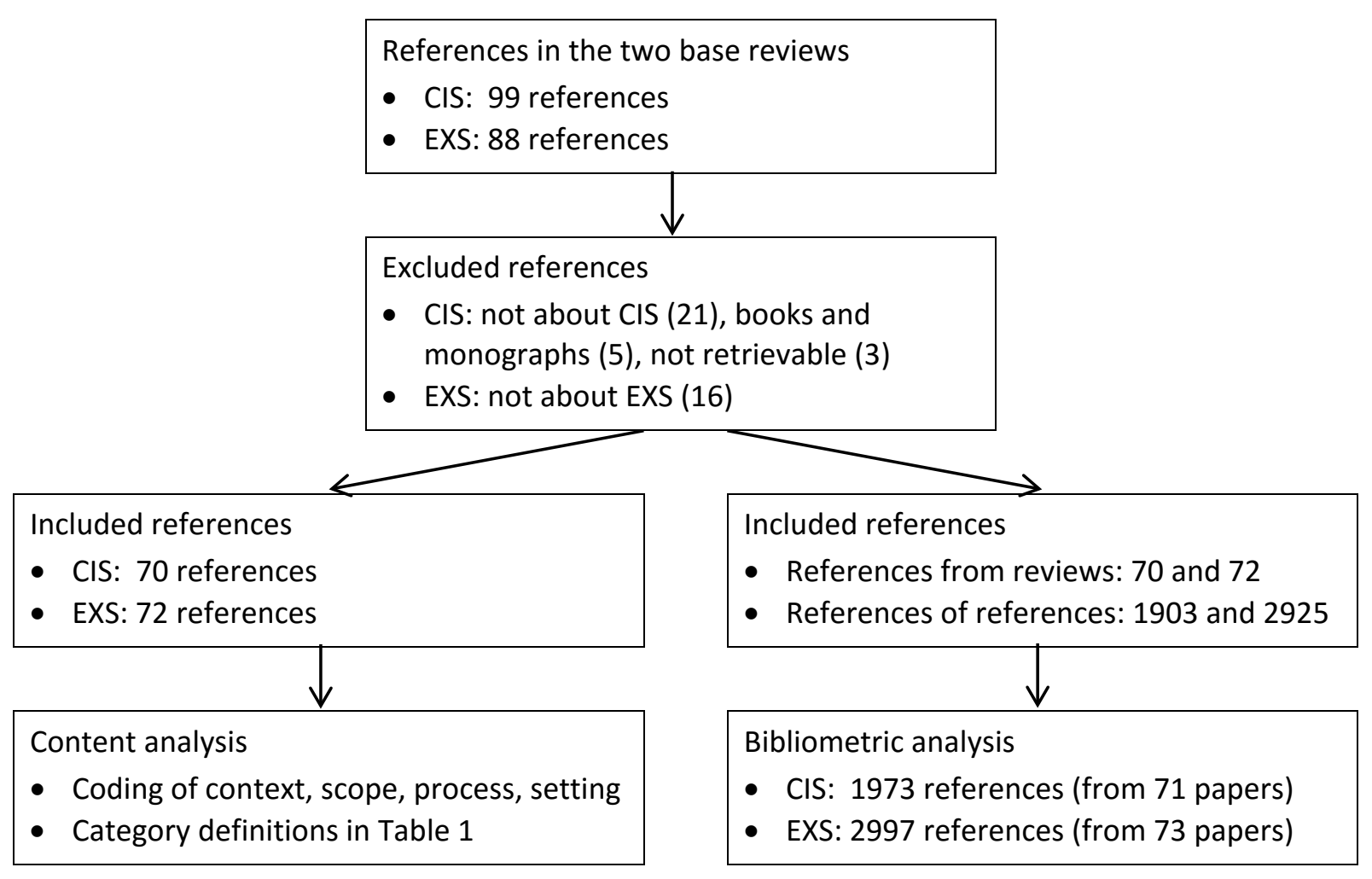

Figure 1. The reference selection process

CIS - Collaborative information seeking, EXS - Expertise seeking. 

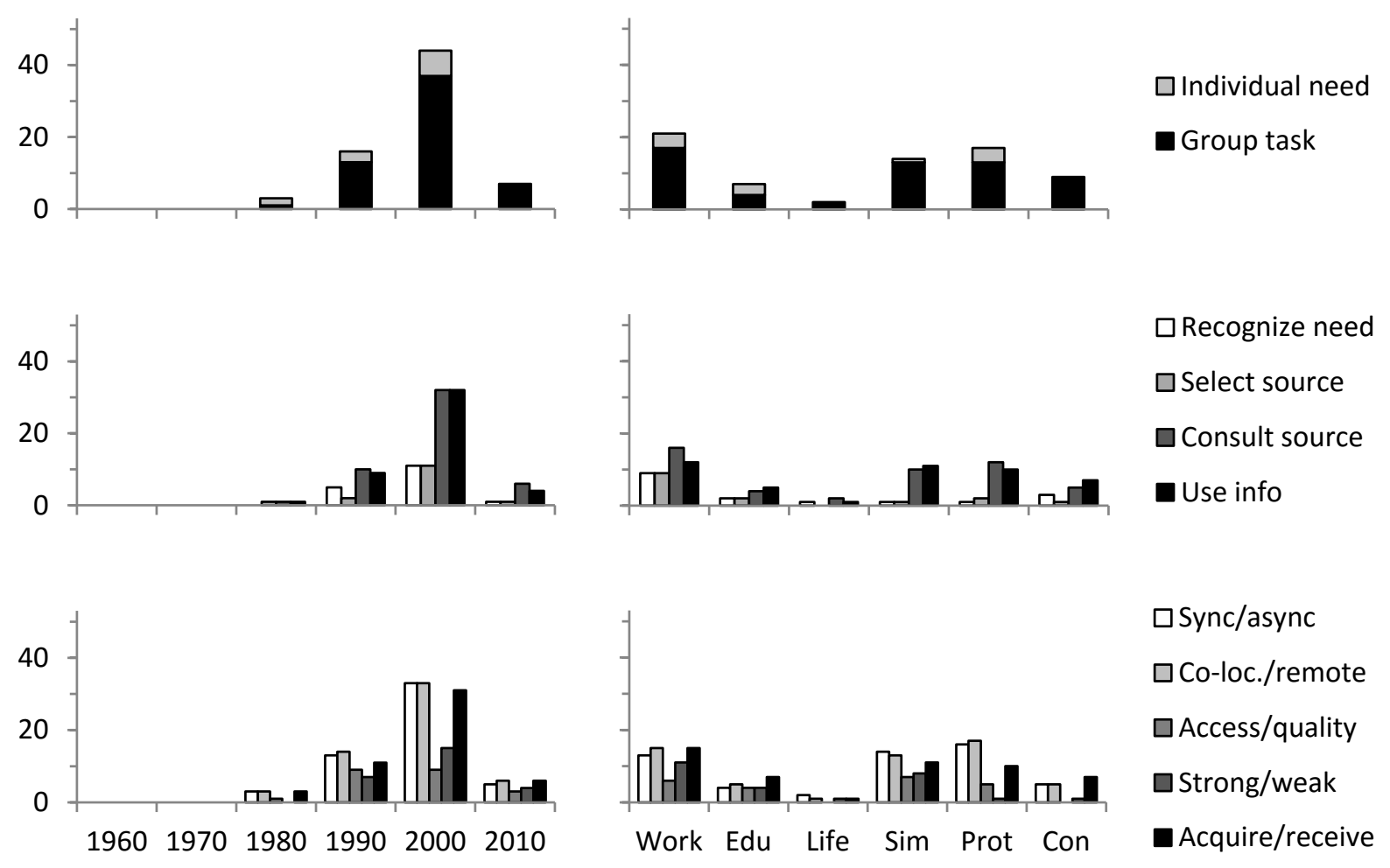

Figure 2. The 70 papers about collaborative information seeking divided onto publication decade (left) and setting (right) for each context (top), scope (middle), and process (bottom) category. Note that for the 2010 s the reviewed papers cover only the first years of the decade. 

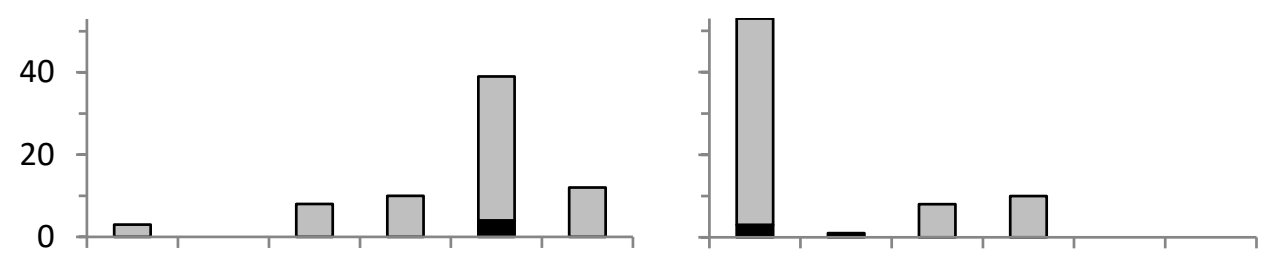

$\square$ Individual need

- Group task
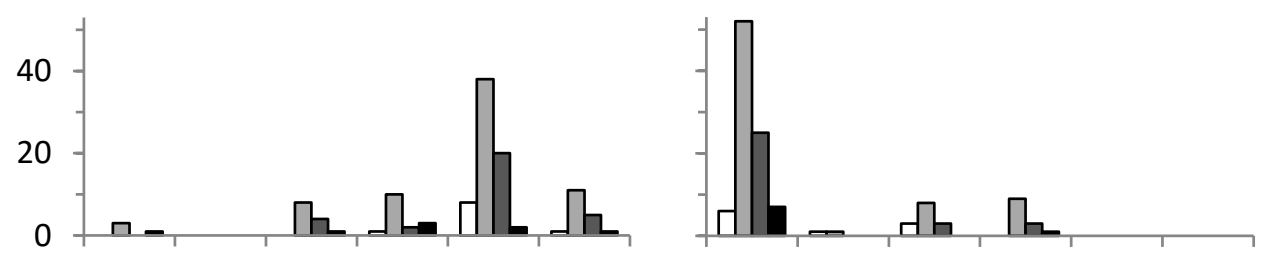

$\square$ Recognize need

$\square$ Select source

$\square$ Consult source

Use info
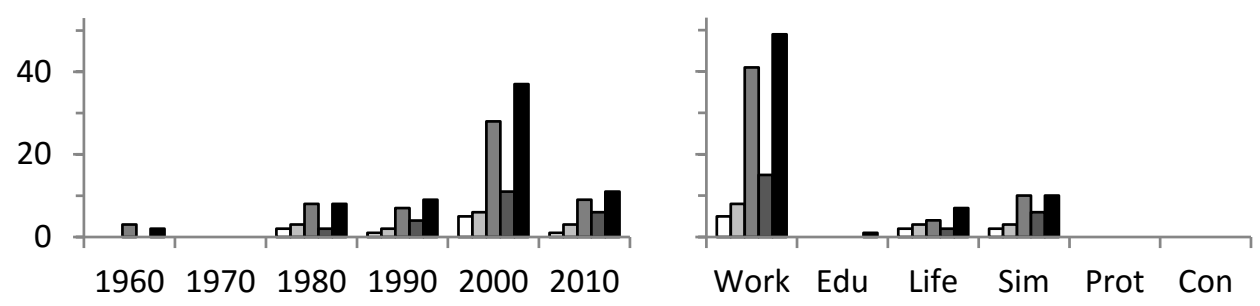

$\square$ Sync/async
$\square$ Co-loc./remote
$\square$ Access/quality
$\square$ Strong/weak
Acquire/receive

Figure 3. The 72 papers about expertise seeking divided onto publication decade (left) and setting (right) for each context (top), scope (middle), and process (bottom) category. Note that for the 2010s the reviewed papers cover only the first years of the decade. 
Recognizing need

\section{CIS}

Selecting source

Consulting source

Using information

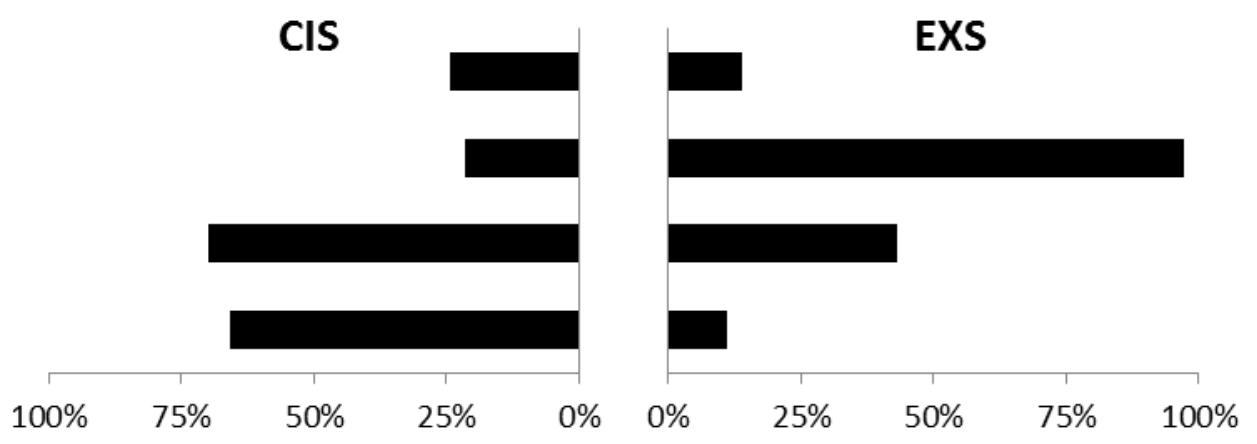

Figure 4. The scope of collaborative information seeking (CIS) and expertise seeking (EXS) 


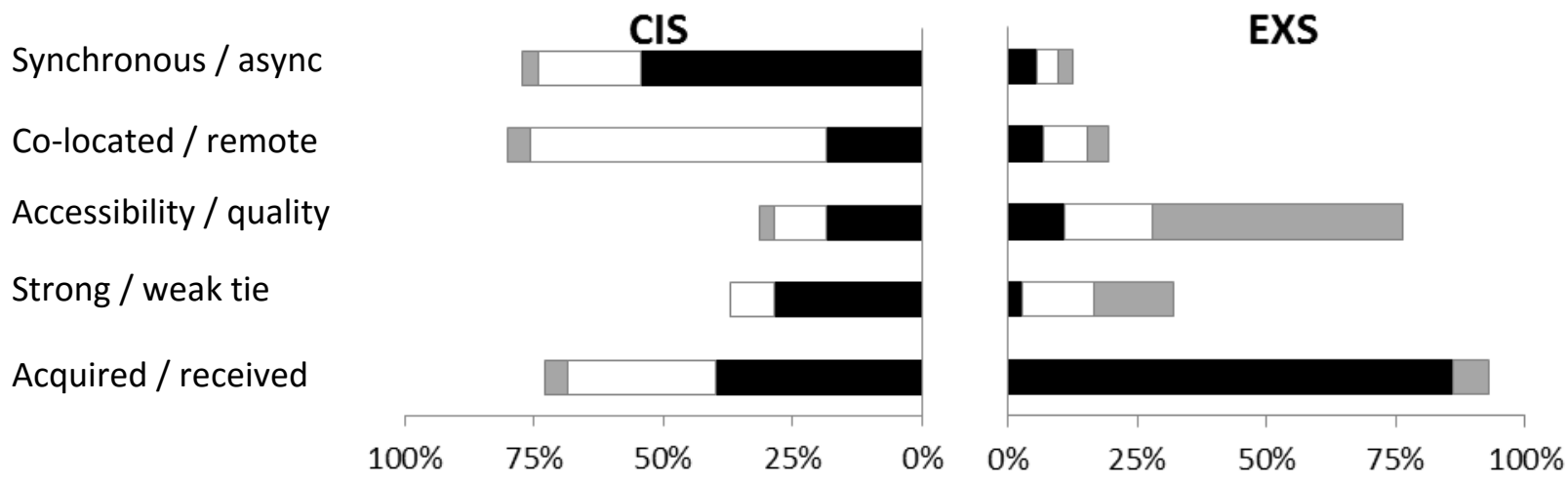

Figure 5. The process of collaborative information seeking (CIS) and expertise seeking (EXS)

Note. The black bars indicate the studies of the first descriptor (e.g., synchronous), the white bars indicate the studies of the second descriptor (e.g., asynchronous), and the grey bars indicate the studies that compare the two descriptors. 


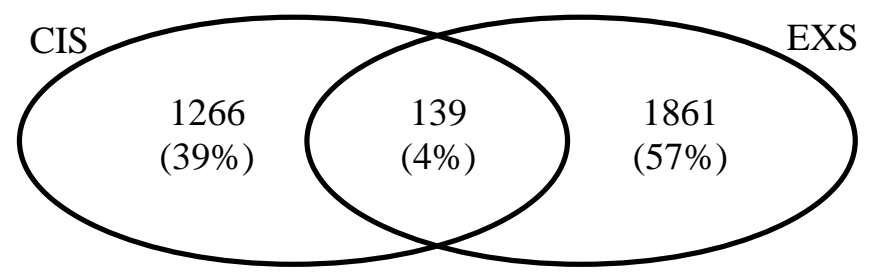

Figure 6. Distribution of the 3266 unique references onto collaborative information seeking (CIS) and expertise seeking (EXS) 